\title{
SPATIOTEMPORAL DISTRIBUTION CHARACTERISTICS OF SOIL EROSION IN THE LOWER REACHES OF THE CHISHUI RIVER BASIN, CHINA
}

\author{
WANG, X. ${ }^{1}-$ LI, S. D. ${ }^{1 *}-$ LIU, H. H. ${ }^{1}-$ LIU, Y. Y. ${ }^{1,2}$

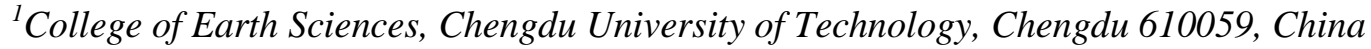 \\ ${ }^{2}$ Earth and Environmental Department, University of West Florida, Pensacola 32514, USA \\ *Corresponding author \\ e-mail:2793213288@qq.com
}

(Received 12 $2^{\text {th }}$ Dec 2019; accepted $6^{\text {th }}$ May 2020)

\begin{abstract}
Soil erosion leads to a decrease in land productivity, and a series of ecological and environmental security problems. China is one of the most susceptible country to severe soil erosion in the world. The spatial-temporal differentiation of soil erosion is the precondition to understand the regional soil erosion, which reflects the spatial and temporal variation of soil erosion. This paper took the lower reaches of the Chishui River Basin as the research area and the 2000-2015 period as the time interval of the study. The article considers the impact factors in the revised General Soil Loss Equation (RUSLE), and comprehensively evaluates the spatial distribution of soil erosion sensitivity. According to national standards, the soil erosion in the basin can be divided into six grades. At the same time, the GIS software platform was used to analyze the changing trend of water and soil loss in the basin during the 15 years. The quantitative driving force analysis of soil and water loss in the study area was carried out by using a geo-detector. Soil erodibility factor is the main driving force for soil erosion.
\end{abstract}

Keywords: RUSLE, change slope method, GIS, soil erosion, geo-detector

\section{Introduction}

Soil erosion can destroy land resources (Ochoa et al., 2016), reduce land productivity (Rodrigo-Comino et al., 2016), increase riverbed (Gogichaishvili et al., 2014), silt rivers (Abidin et al., 2017), exacerbate floods (Osouli and Bahri, 2018) and droughts (Kosmowski, 2018). Soil erosion is posing an increasing threat to soil structure (Kosmas et al., 2000), sustainable agricultural development (Montgomery, 2007), Water quality (Khaledian et al., 2017) and the global environment (Cerdà et al., 2018). This became one of the most serious problems all over the world. China is one of the countries with the most serious soil erosion in the world. The area of soil erosion is as high as $3.56 \times 106 \mathrm{~km}^{2}$, accounting for $37 \%$ of the total land area. The annual loss of topsoil is more than 5 billion tons. The soil nutrient loss is equivalent to the annual fertilizer production in China (Sheng and Shi, 2001). Among them, the area of hydraulic erosion is $1.65 \times 106 \mathrm{~km}^{2}$, and the area of wind erosion is $1.91 \times 106 \mathrm{~km}^{2}$. Soil erosion is the greatest in Sichuan Province in China. The areas of water erosion and wind erosions are $11.442 \times 104 \mathrm{~km}^{2}$ and $0.6622 \times 104 \mathrm{~km}^{2}$, respectively (Wang and Wang, 2011).

Soil erosion is affected and restricted by many factors (Borrelli et al., 2017), some are natural factors such as climate, topography, soil, vegetation, etc., and the other part is human activity factors, such as land use, soil and water conservation measures, etc. Under the combined effect of both natural factors and human activities, soil erosion presents regional differentiation in spatial distribution, and agricultural soil erosion can 
disrupt the global carbon cycle and affect sustainable development (Montgomery, 2007). Recently, soil erosion assessment has been included in the United Nations Environment Programme (UNEP) report on the sustainable potential of land resources (Panagos and Katsoyiannis, 2019). Therefore, it is important to study the regional differentiation characteristics of soil erosion to guide the prevention and control of regional soil erosion. In recent years, GIS and remote sensing technologies have developed rapidly, which provides strong technical support for relevant research on the ecological environment (Pham et al., 2018). The USLE (Universal Soil Loss Equation) has been officially promoted in the US Department of Agriculture Agricultural Handbook No. 282 in 1965. This model is usually used in loss research of the watersheds within the basin (Wischmeier, 1965) and under different evaluation units (Singh and Panda, 2017). GIS software is used to predict soil erosion (Abdulkareem et al., 2019), grade according to soil erosion intensity (Bera, 2017), and take effective control measures for key erosion areas (Uri, 2001; Fenta et al., 2016). Since the USLE model is an empirical model, it has been proved that it is not suitable for ridge cropping, contour farming, and strip-type farming measures for sediment deposition. Soil erosion research experts decided to use the latest research and computer technology (Mondal et al., 2018) to re-improve the USLE in different directions (Preetha and Al-Hamdan, 2019), the most widely used of which is RUSLE (The Revised Universal Soil Loss Equation) (Wijesundara et al., 2018; Mahala, 2018). Based on the GIS platform (Cunha et al., 2017), the RUSLE and SWAT models (Lakkad et al., 2018), SCS-CN method (Kayet et al., 2018), SEDD model (Fu et al., 2006) and other models are combined to effectively simulate the soil erosion process.

The Chishui River Basin is developed in southwestern China and it is a large tributary on the southern bank of the upper reaches of the Yangtze River. The Chishui River Basin is located in the transitional zone between the Yunnan-Guizhou Plateau and the Sichuan Basin. It is an important ecological barrier in the upper reaches of the Yangtze River and plays an important role in the ecological security construction of Sichuan Province (Wang et al., 2007). At the same time, the surface of the basin is undulating, with relatively large differences in height and complex geological structures. It is an ecologically sensitive and vulnerable area with an important ecological function. Besides, due to the long-term unreasonable development and utilization of hydropower, forestry, minerals, agriculture and animal husbandry, and other resources it has not only failed to fully exert its ecological barrier function but instead, it has become a prominent area for soil erosion problems, which has threatened the safety of Sichuan Province and the entire Yangtze River Basin. It is of great strategic significance to protect and construct the ecological environment of the basin. The quantitative evaluation of the trend of soil erosion before and after the implementation of the ecological engineering of the basin is aimed at grasping the impact of environmental engineering on soil erosion improvement, to provide a scientific basis for further planning and implementation of ecological engineering in the basin. The main objectives of this study are as follows: (1) The slope method based on the ecological environment vulnerability is combined with the RUSLE model for dynamic monitoring of long-term sequences; (2) Based on the regression status of soil erosion, the trend is predicted; (3) Geographic detector model is widely used in natural and social sciences. This paper uses it to explore the relative importance and interaction between the driving forces of factors affecting soil erosion in the long time series of the study area; (4) Accurate assessment of the temporal and spatial distribution of soil 
erosion will contribute to the sustainable use of land resources. According to the research results, suggestions for prevention and treatment of future soil erosion in the Chishui River Basin are proposed.

\section{Materials and methods}

\section{Study area}

The study area is located between $105^{\circ} 08^{\prime} \mathrm{E}-106^{\circ} 28^{\prime} \mathrm{E}$ to $27^{\circ} 39^{\prime} \mathrm{N}-29^{\circ} 01^{\prime} \mathrm{N}$, covers an area of $9796.13 \mathrm{~km}^{2}$ (Fig. 1). It is located in the transitional zone between the southern margin of the Sichuan Basin and the Yunnan-Guizhou Plateau. The terrain is higher in the north and lowers in the south. The northern part of the area involves mostly valleys, low-lying hills and flat dams, which is a land flowing with tea, bamboo shoots and litchi. The southern part of study area is connected to the Yunnan-Guizhou Plateau and belongs to the northern foot of Ta-lou Mountains. The landform of this place is low mountain cut deeply by the river. The geological structure of the study area is complex, and the strata are dominated by various sedimentary rocks, so the mineral resources are rich and diverse. There are more than 20 proven minerals, such as coal, oil, natural gas, pyrite, iron, copper, gold, refractory clay, solvent dolomite, limestone for cement, kaolin, phosphorus, sand for glass, gypsum, marble, calcite, etc. (Cai et al., 2015). The climate type is humid subtropical climate, which shows its typical characteristics in Southern mountainous region. The average annual temperature is about $18.0^{\circ} \mathrm{C}$, the average temperature in the coldest month (January) is about $7{ }^{\circ} \mathrm{C}$, the average temperature in the hottest month (July) is about $27^{\circ} \mathrm{C}$, the extreme maximum temperature can reach $40{ }^{\circ} \mathrm{C}$, and the extreme minimum temperature is about minus $1{ }^{\circ} \mathrm{C}$ (Chen and Tong, 2012). However, due to the topography of the Sichuan basin, The Chishui River Basin is rich in rainfall, with annual rainfall of about $1000 \mathrm{~mm}$, mainly concentrated in May-September, accounting for more than $75 \%$ of the total annual rainfall. The frost-free period in this area is longer than 300 days, so it is suitable for long growing periods of crops.

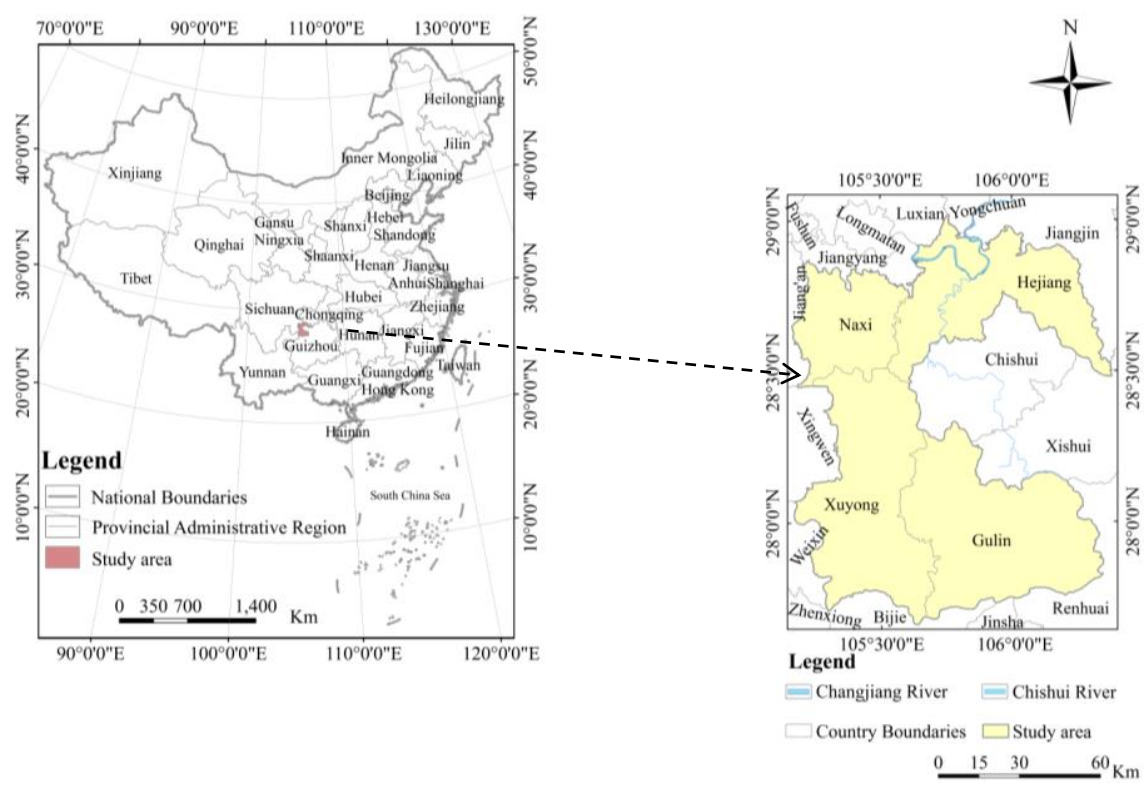

Figure 1. Location of the study area 


\section{Materials}

Topographic factor (LS) (Alexakis et al., 2013). The terrain is one of the most basic elements of natural geography. It is also one of the important factors determining the intensity and type of soil erosion. Topographic factors such as slope direction, slope (Hickey et al., 1994), slope length (Kayet et al., 2018), and undulation degree directly affect the occurrence of soil erosion. Slope factor and slope length factor are important topographic factors that lead to soil erosion. It is difficult to cause a lot of soil erosion in areas with slow slopes, and it is more likely to occur in areas with steep slopes. For example, the soil erosion in the southwestern mountainous areas of China is serious, while the intensity of soil erosion is relatively low in some basins and plains. The slope factor quantitatively reflects the relationship between the slope and the amount of soil loss (Liu et al., 2000). The slope length refers to the projected length of the distance from a point along the direction of water flow to the end point under the action of gravity on the horizontal plane. Slope length factor is one of the important landforms that affects runoff from slopes, and it quantitatively reflects the relationship between slope length and soil loss. The LS factor is extracted from the $30 \mathrm{~m}$ spatial resolution digital elevation model (DEM) data provided by geospatial data cloud (http://www.gscloud.cn). Equation 1 is the slope formula:

$$
S=\left\{\begin{array}{l}
10.8 \times \sin \theta+0.036 \quad \theta<5^{\circ} \\
16.8 \times \sin \theta-0.5 \quad 5^{\circ} \leq \theta<10^{\circ} \\
21.9 \times \sin \theta-0.96 \quad \theta>10^{\circ}
\end{array}\right.
$$

Since the $\mathrm{S}$ in the formula is radian, so it is necessary to turn the angle unit into radian according to Equation 2:

$$
L=(\lambda / 22.13)^{\mathrm{m}}
$$

where $\lambda$ is slope length, and $\mathrm{m}$ is slope length factor, the range of the value of $\mathrm{m}$ is shown as Equation 3:

$$
\mathrm{m}= \begin{cases}0.2 & \theta<1^{\circ} \\ 0.3 & 1^{\circ}<\theta \leq 3^{\circ} \\ 0.4 & 3^{\circ}<\theta \leq 5^{\circ} \\ 0.5 & \theta>5^{\circ}\end{cases}
$$

Using the analysis function of ArcGIS 10.2 software, the distribution of L factor and $\mathrm{S}$ factor in the study area were obtained (Fig. 2).

Rainfall erosivity factor $(R)$ (Schmid, 2012). Rainfall is a factor affecting soil erosion. During rainfall, the kinetic energy of the raindrops splashing on the soil particles, cause runoff and soil erosion. The value of rainfall erosivity factor is related to rainfall dynamics and intensity. Rainfall erosivity is a function of rain pattern, raindrop kinetic energy, rainfall, and rainfall intensity. It is the potential for soil erosion caused by precipitation (Efthimiou, 2018). By comparing the method of calculating rainfall erosivity by domestic and foreign scholars, we chose the most suitable formula for the 
study area (Wu et al., 2001). Monthly and annual rainfall data from 2000-2015 meteorological stations in the study area were derived from the China Meteorological Data Network (http://data.cma.cn/). The annual rainfall erosivity of 4 periods was calculated using Equation 4, and the spatial interpolation (kriging interpolation method) was used to calculate the annual rainfall erosivity data. The annual rainfall erosivity map of the study area (Fig. 3) was obtained.

$$
R=\left(\sum_{i=1}^{12}-2.6389+0.3046 P_{i}\right) \times 17.2
$$

where Pi represents the average monthly rainfall over many years ( $\mathrm{mm}$ ).

Soil erodibility factor $(K)$. Soil erosion is mainly affected by various physical and chemical characteristics of the soil itself, such as permeability, texture, structure, stability of aggregates, organic matter content, compactness, particle composition, properties of clay minerals, soil thickness and chemical composition. It is an indispensable parameter in the soil erosion model (RUSLE) (Torri et al., 1997). Soil erosion is the separation and transport of soil particles (Buttafuoco et al., 2012) caused by the combined action of hydraulic and wind forces (Rammahi and Khassaf, 2018). Data of 1:100 soil types in the watershed study area, including physical and chemical data from various soil types, are derived from China soil database. This paper selects the EPIC Equation 5 to calculate soil erodibility factors in the study area:

$$
K_{E P I C}=\left\{\begin{array}{l}
0.2+0.3 \exp \left[0.256 \operatorname{SAN}\left(1-\frac{S I L}{100}\right)\right] \times\left(\frac{S I L}{C A L+S I L}\right)^{0.3} \\
\times\left[1-\frac{0.25 C}{C+\exp (3.72-2.95 C)}\right] \times\left[1-\frac{0.75 S N 1}{S N 1+\exp (-5.51+22.9 S N 1)}\right]
\end{array}\right\}
$$

Among them, Equation 6 is used to calculate SN1:

$$
S N 1=\frac{S A N}{100}
$$

where SAN represents gravel $(0.05-2.0 \mathrm{~mm})$ content $(\%)$; SIL $(0.002-0.05 \mathrm{~mm})$ is the content of powder $(\%)$; CLA $(<0.002 \mathrm{~mm})$ is the clay content $(\%)$ in the soil; $\mathrm{C}$ is the percent organic matter. We perform a small operation on the $\mathrm{K}$ value obtained after the calculation and convert the U.S. unit into an international unit: K (U.S unit) $\times 0.1317=\mathrm{K}$ (international unit). Since the soil properties in China are quite different from those in the United States, the revised EPIC Equation 7 is used to estimate the K value of soil erodibility in the study area:

$$
K=-0.1383+0.051575 K_{E P I C}
$$

where $K$ is the corrected soil erodibility value and $K_{E P I C}$ is the soil erodibility value estimated using the EPIC formula.

Soil erodibility also reflects the sensitivity of the soil itself to erosion by external forces. Under the same conditions, the greater the soil erodibility, the more easily the soil is eroded, and the less soil erodibility is, the less likely the soil is to be eroded. Through 
the above formula, the $\mathrm{K}$ value of each soil type in the lower reaches of the Chishui River is calculated (Fig. 4). From the figure, we can see that the overall soil erodibility $\mathrm{K}$ value sensitivity is low, and the average sensitivity to the erosion process is low. Because of the good stability of soil particle size, there are no major changes in the period of the study. Therefore, only one stage data is needed for a comprehensive study.
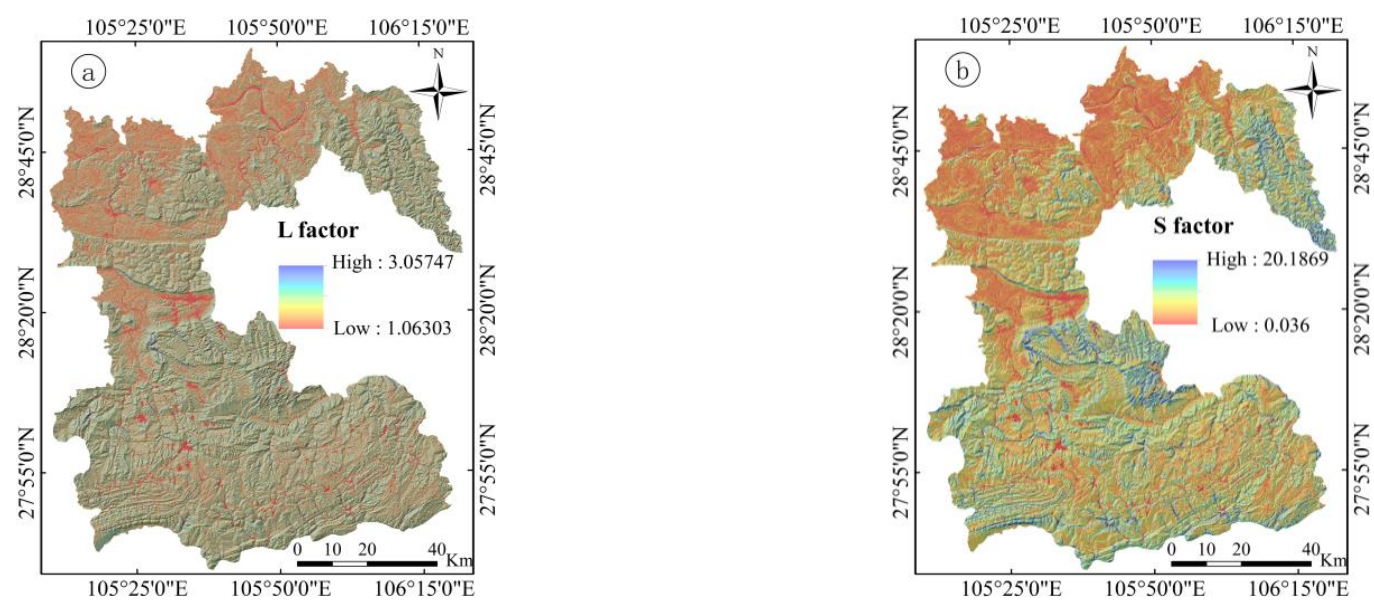

Figure 2. L, S factor in the study area
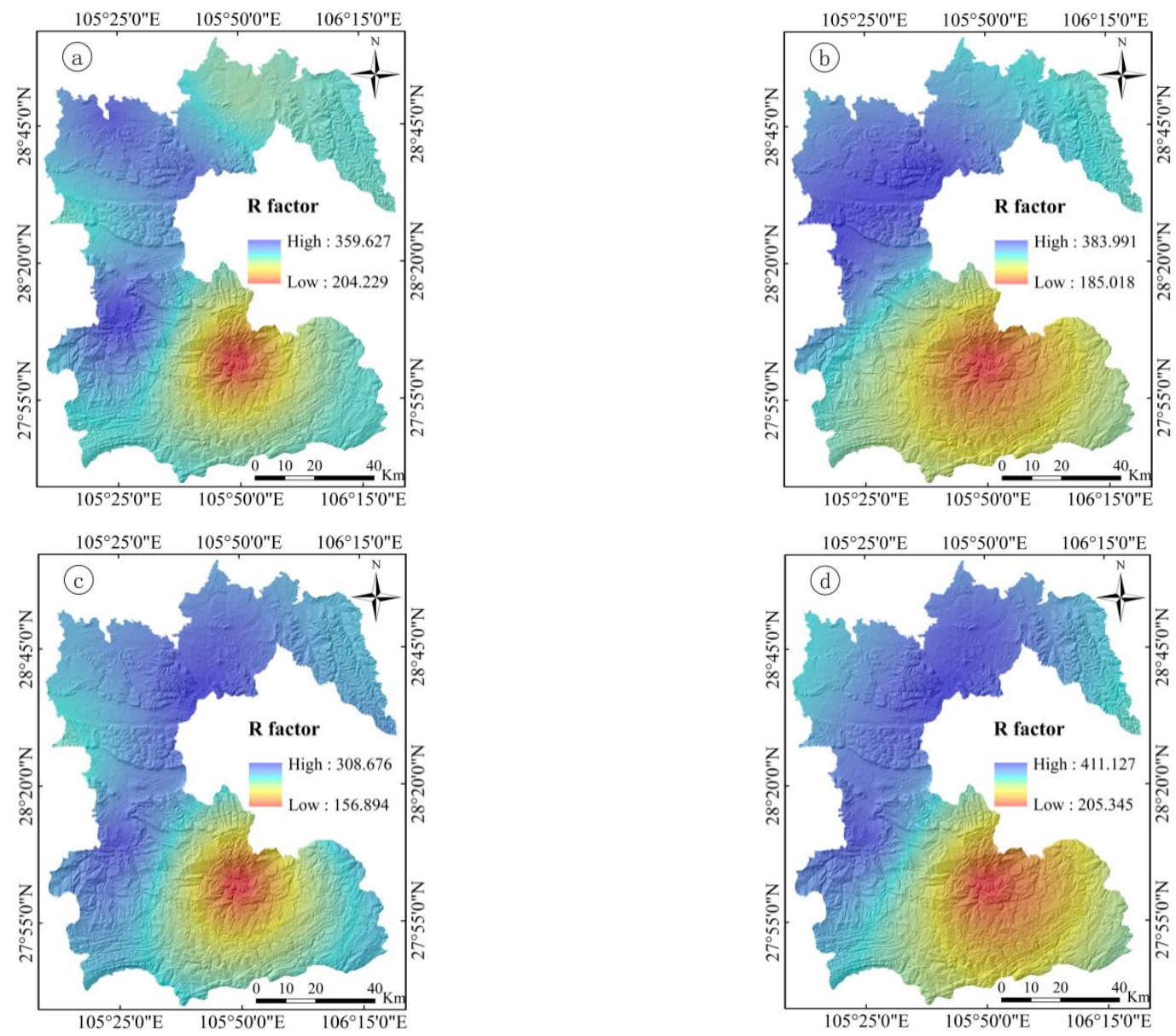

Figure 3. L, S factor in the study area. Spatial distribution of rainfall erosivity in 2000 (a), 2005

(b), $2010(c), 2015(d)$ 


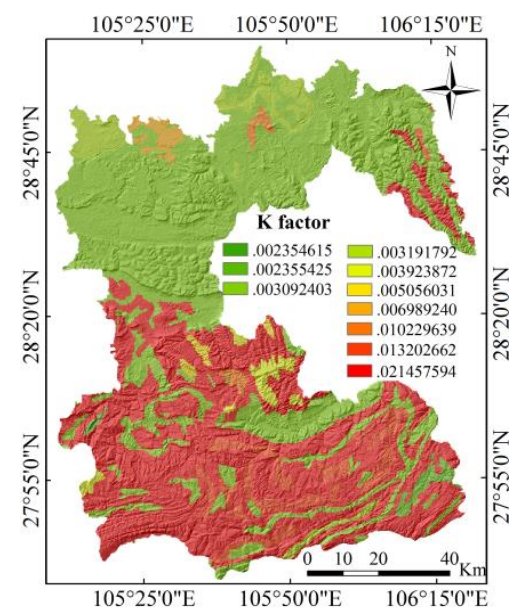

Figure 4. Spatial distribution of soil erosivity factor in the study area

Vegetation cover management factor $(C)$. Vegetation coverage and management factors refer to the comprehensive effect of soil erosion on the change of vegetation coverage in natural conditions. We use the vegetation index conversion method to analyze the vegetation types and distribution characteristics in each pixel to establish the conversion relationship between the vegetation index and the vegetation coverage to obtain the vegetation coverage. At present, this method is relatively mature, and its advantage is that it is easy to operate and implement remote sensing monitoring of vegetation coverage on a regional scale. The MODIS data was obtained from the geospatial data cloud (http://www.gscloud.cn), and the data was processed by MVC maximum value synthesis. Finally, pixel bisection was used to extract NDVI data. Using Equation 8 established (Cai, 2000) to calculate the $\mathrm{C}$ value of the study area:

$$
C=\left\{\begin{array}{l}
1 \quad c=0 \\
0.6508-0.3634 \lg c \quad 0<c<78.3 \% \\
0 \quad c \geq 78 . \%
\end{array}\right.
$$

where $C$ is the vegetation cover and management factor, $c$ is the vegetation coverage. When the $c$ value is greater than or equal to $78.3 \%$, the $C$ value is equal to 0 , indicating that no soil erosion has occurred on the ground surface. When the $c$ value is equal to 0 , the $C$ value is equal to 1 , indicating that the surface soil erosion is severe. In the range of 0 to 1 , as the $C$ value increases, the surface soil erosion becomes more severe. Using the ArcGIS Raster Calculator, the Distribution of Vegetation Coverage and Management Factors from 2000 to 2015 (Fig. 5).

Soil and water conservation practice factor $(P)$ (Karydas et al., 2009). It is a quantitative indicator used to reflect the degree of influence of soil and water conservation measures on soil erosion. Specifically, it refers to the ratio of the amount of soil and water loss after the implementation of soil and water conservation measures to the amount of soil and water loss without any soil and water conservation measures for a certain soil and water loss area under the same conditions. The value ranges from 0 to 1 . When the $\mathrm{P}$ value is 0 , no soil erosion occurs in the study area. When the $\mathrm{P}$ value is 1 , it indicates that no soil and water conservation measures have 
been taken in the study area, and soil erosion is serious. The existing method of determining the P-value was mainly obtained through experience (Vaezi et al., 2017). This article obtained the land use (Anache et al., 2018) data of 4 years' spatial resolution of $30 \mathrm{~m}$ from the resources and environmental science data center of the Chinese Academy of Sciences (http://www.resdc.cn) and looked up the information of the predecessors (Kavian et al., 2015). We have consulted previous data and assigned a value of 1 to land use types such as forest land, shrubs, grasslands, and unused land that could be considered as not having any soil and water conservation measures. And land use types such as water bodies, towns and construction land, which did not cause soil erosion in principle, were assigned a value of $0,0.1$ for water and land, and 0.35 for dry land. Form all of this, we could get the distribution of soil and water conservation measures factors as shown in Figure 6.
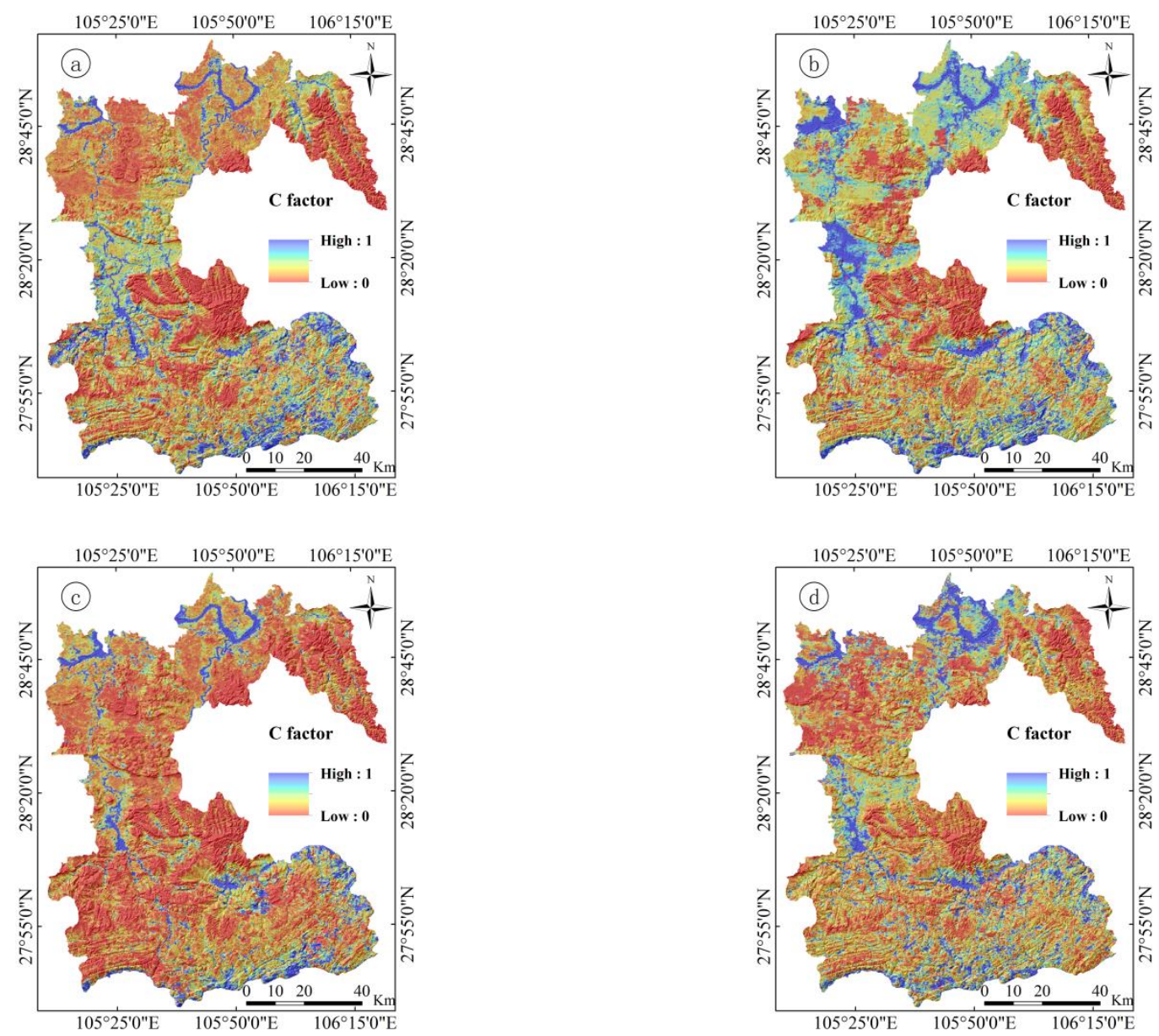

Figure 5. Spatial distribution of land cover and management factors in the study area in 2000 $(a), 2005(b), 2010(c), 2015(d)$

\section{Methods}

\section{RUSLE model}

The concept of soil processes (Ostovari et al., 2017) was introduced base on the USLE equation (Leys et al., 2010). After correction, a more comprehensive soil erosion loss (RUSLE) Equation 9 was obtained (Das et al., 2018). 


$$
A=R \times K \times L \times S \times C \times P
$$

where $\mathrm{A}$ is the annual soil erosion modulus $\left(\mathrm{t} /\left(\mathrm{hm}^{2} \cdot \mathrm{a}\right)\right)$; $\mathrm{R}$ is the rainfall erosivity factor $\left(\mathrm{MJ} \cdot \mathrm{mm} /\left(\mathrm{hm}^{2} \cdot \mathrm{h} \cdot \mathrm{a}\right)\right) ; \mathrm{K}$ is soil erodibility factor $\left(\mathrm{t} \cdot \mathrm{hm}^{2} \cdot \mathrm{h} /\left(\mathrm{hm}^{2} \cdot \mathrm{MJ} \cdot \mathrm{mm}\right)\right)$; LS is slope length and slope factor; $\mathrm{C}$ is vegetation cover and management factor; $\mathrm{P}$ is soil and water conservation factor.
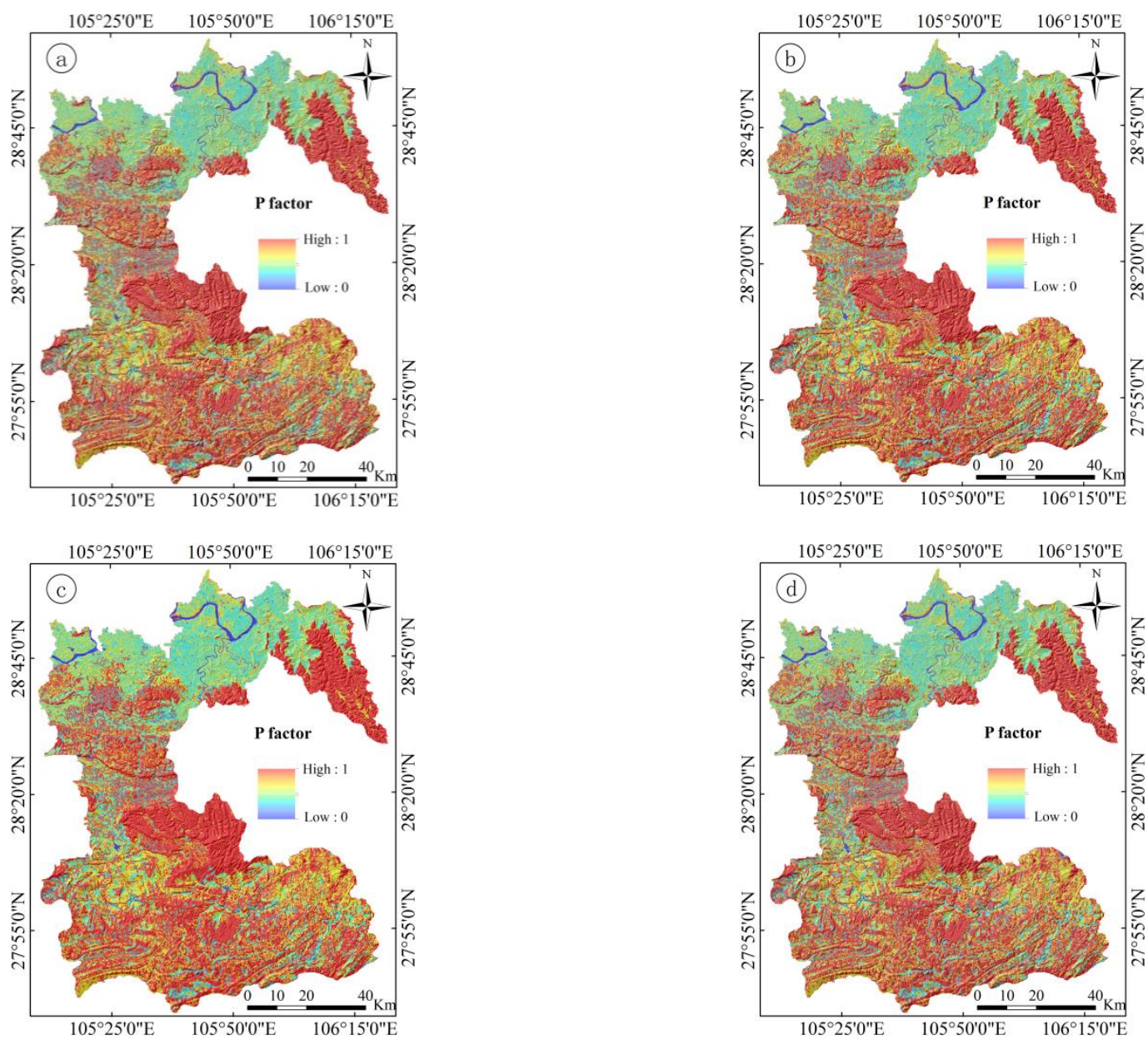

Figure 6. Spatial distribution of soil and water conservation in the study area from 2000 to 2015

\section{Change slope method}

The change slope method (Yang et al., 2018) is the regression analysis of a group of time-varying variables and predicts the trend of their change (Krellenberg and Welz, 2017). This method uses the least squares method to calculate the regression line between the annual soil erosion modulus sequence and time of all the pixels on the data set. The result is a slope image. It expresses the linearity of the annual soil erosion modulus represented by each pixel on the image. In China, it is widely used in ecological vulnerability research. This paper uses this method to simulate the interannual change of soil erosion, that is, to use the least-squares method to regression fit the annual soil erosion model values and time. Before the operation, the annual soil 
erosion modulus is standardized between $0-1$. It is convenient for the next comparison. Equation 10 of the variation slope method is shown as follows:

$$
X=\frac{n \times \sum_{i=1}^{n} i \times A_{i}-\left(\sum_{i=1}^{n} A_{i}\right)}{n \times \sum_{i=1}^{n} i^{2}-\left(\sum_{i=1}^{n} i^{2}\right)}
$$

where $\mathrm{X}$ is the change slope; $\mathrm{n}$ is the number of years $\mathrm{Ai}$ is the soil erosion modulus in a year $i$. The slope is positive, indicating that the soil erosion is increasing; the slope is negative, indicating that the soil erosion is decreasing. The significance test of the changing trend uses the $\mathrm{F}$ test $(E q .11)$. The statistics are calculated as follows:

$$
F=U \times \frac{n-2}{Q}
$$

where $Q=\sum_{i=1}^{n}\left(y_{i}-\hat{y}_{i}\right)^{2}$ is the square root of error; $U=\sum_{i=1}^{n}\left(\hat{y_{i}}-\hat{y}_{i}\right)^{2}$ is regression square sum; $\mathrm{y}_{i}$ is the actual value of soil erosion modulus for the year $\mathrm{I} \mathrm{y}_{i}$ is the regression value of soil erosion modulus in the year I; $y_{i}$ is the regression value of soil erosion modulus in the year $\mathrm{i}$. According to the changing trend and significance level of soil erosion modulus $\mathrm{A}$, the change trends were divided into three categories: significant increase $(X>0, P<0.05)$, a significant decrease $(X<0, P<0.05)$, and no significant change $(\mathrm{P} \geq 0.05)$.

\section{Principles and applications of the geographical detector}

The Geo-Detector is a new statistical method used by the Chinese Academy of Sciences (Wang and $\mathrm{Xu}, 2017$ ), it investigates spatial differentiation and tries to explain potential drivers that affect its geographic phenomena. Compared with the traditional correlation analysis method, the geographic detector does not need too many assumptions, and avoids the defects of some methods in processing category traversal. It can be used to detect both numerical data and qualitative data. It can also effectively analyze the two quantitatively. The geographic detector does not need to consider the problem of collinearity of multiple variables, and it is more clear than the physical meaning of analysis of variance. It can also detect the real situation of the interaction of two variables, including non-linear enhancement, mutual independence, two-factor enhancement, and single-factor non-linear attenuation. The geography detector is mainly composed of four parts: "risk detector, factor detector, ecological detector, and interaction detector". This paper uses the factor detector to detect and analyze the soil in the lower reaches of the Chishui River Basin from 2005 to 2015. Quantitative correlation was investigated between erosion and its driving factors.

Factor detector: detecting the efficiency of the evaluation index $X$ that can explain the dependent variable $Y$, this can be quantified by index $Q_{D, H}$. The larger the value is, 
the greater the contribution to soil erosion will be, and vice versa. The statistical model is shown in Equation 12:

$$
Q_{D, H}=1-\frac{1}{n \sigma^{2}} \sum_{h=1}^{L} n_{h}^{2} \sigma
$$

where $\mathrm{D}$ indicates the evaluation index, $\mathrm{H}$ indicates the amount of soil erosion, $\mathrm{Q}_{\mathrm{D}, \mathrm{H}}$ indicates the explanatory power of the evaluation index factor on soil erosion, ranging from $0-1, \mathrm{n}$ indicates the number of samples, $\mathrm{L}$ indicates the number of indicators, $\mathrm{nh}$ indicates the $\mathrm{h}$ layer sample Quantity, $n_{h}^{2}$ represents the variance of the amount of soil erosion in the layer.

\section{Results}

\section{Spatiotemporal analysis of soil erosion}

In order to unify the investigation of soil and water loss and carry out soil and water conservation work, the Ministry of Water Resources of the People's Republic of China has formulated the classification of soil erosion applicable to the whole country. There are three types of soil erosion in the country: hydraulic erosion, wind erosion, and freeze-thaw erosion. The Chishui River Basin is located in the southern fringe of Sichuan Province and belongs to the southwestern earth and rock mountain area. It is dominated by hydraulic erosion. According to the "Classification Standard of Soil Erosion". We divided the soil erosion module in the lower reaches of the Chishui River Basin from 2000 to 2015 into six categories: micro, mild (500-2500 t/( $\left.\mathrm{km}^{2} \cdot \mathrm{a}\right)$ ), moderate $\left(2500-5000 \mathrm{t} /\left(\mathrm{km}^{2} \cdot \mathrm{a}\right)\right)$, strong $\left(5000-8000 \mathrm{t} /\left(\mathrm{km}^{2} \cdot \mathrm{a}\right)\right)$, extremely strong $\left(8000-15000 \mathrm{t} /\left(\mathrm{km}^{2} \cdot \mathrm{a}\right)\right)$, and severe $\left(>15000 \mathrm{t} /\left(\mathrm{km}^{2} \cdot \mathrm{a}\right)\right)$. The unit of soil erosion modulus calculated by RUSLE is $\mathrm{t} /\left(\mathrm{hm}^{2} \cdot \mathrm{a}\right)$, and the unit in the "Classification Standard of Soil Erosion" is $\mathrm{t} /\left(\mathrm{km}^{2} \cdot \mathrm{a}\right)$. So we need to multiply the RUSLE calculation result by 100 and then classify it. The study area was generally in a state of moderate erosion. The spatial distribution characteristics of soil erosion were obvious, showing a pattern of High South and low North (Fig. 7). The areas with slight or below soil erosion were mainly distributed in most areas of Naxi and Hejiang counties. The moderate and strong soil erosion areas were widely distributed in most areas of the southern part of the study area, and the very strong and strong soil erosion areas were concentrated in the intersection of Xuyong county and Gulin county.

By counting the different soil erosion grade areas, the number of soil erosion graded pixels in the lower reaches of the Chishui River Basin from 2000 to 2015 was obtained (Fig. 8). The results show that the overall improvement of soil erosion in the study area in 2015: a large number of areas with moderate erosion have been transformed into micro erosion and light erosion, which shows that the government has achieved preliminary results in land-based management. Grades above moderate erosion have increased slightly. By consulting the data, we can find that in 2015, there were many heavy rains in the lower reaches of the Chishui River Basin, and the daily rainfall of the station reached a maximum of $256.6 \mathrm{~mm}$. Summer rainstorms are concentrated, with a short duration and high intensity, which provides erosive external forces for the occurrence of soil and water loss. Once the vegetation is destroyed, severe soil erosion occurs very easily. The soil developed in the strongly eroded area and the extremely strongly eroded area has good 
water permeability, but the soil layer is shallow. Under the condition of loss of vegetation protection and heavy rainfall, soil erosion is prone to occur.
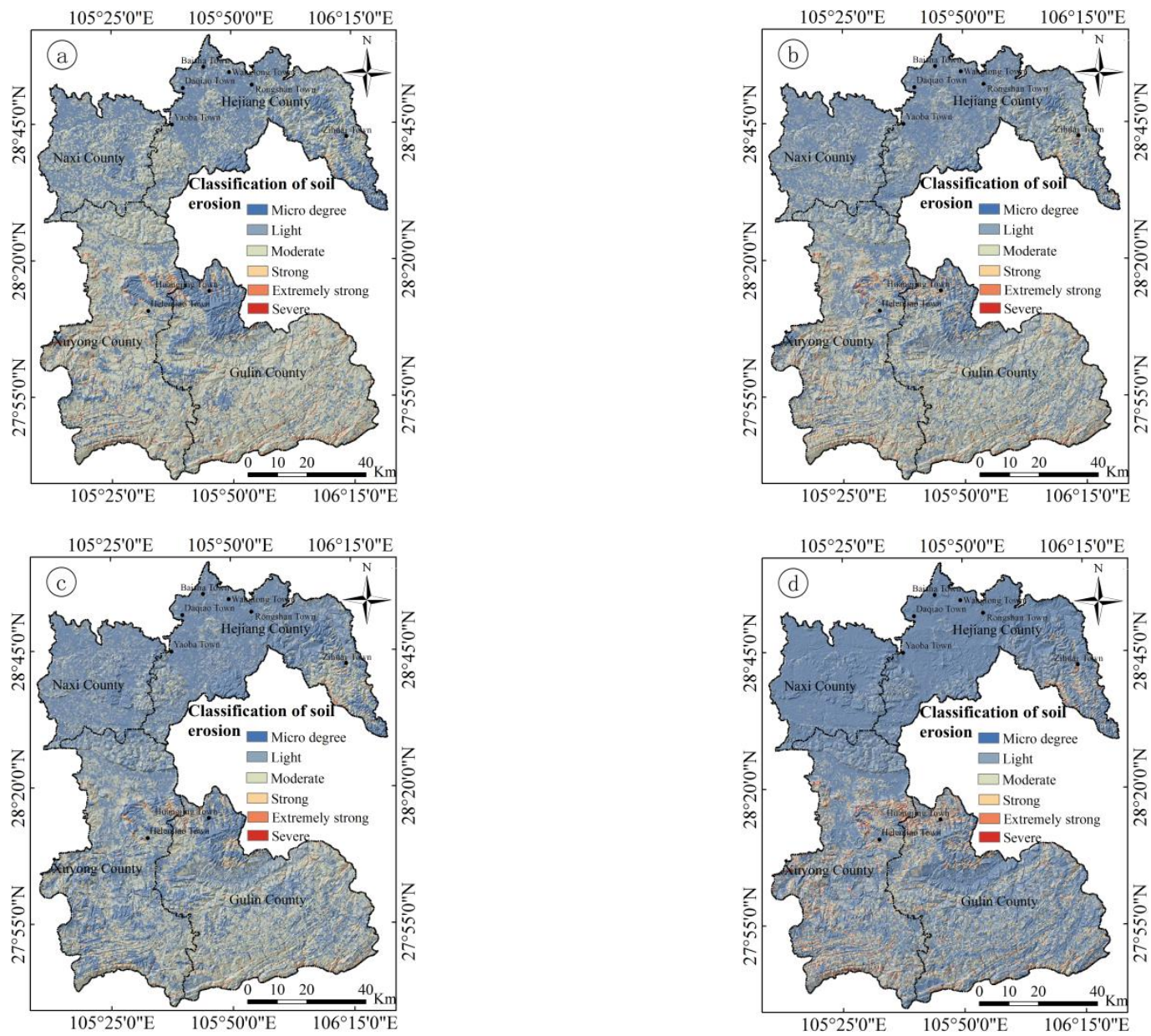

Figure 7. Spatial distribution of soil erosion in the lower reaches of the Chishui River Basin in $2000(a), 2005(b), 2010(c), 2015(d)$

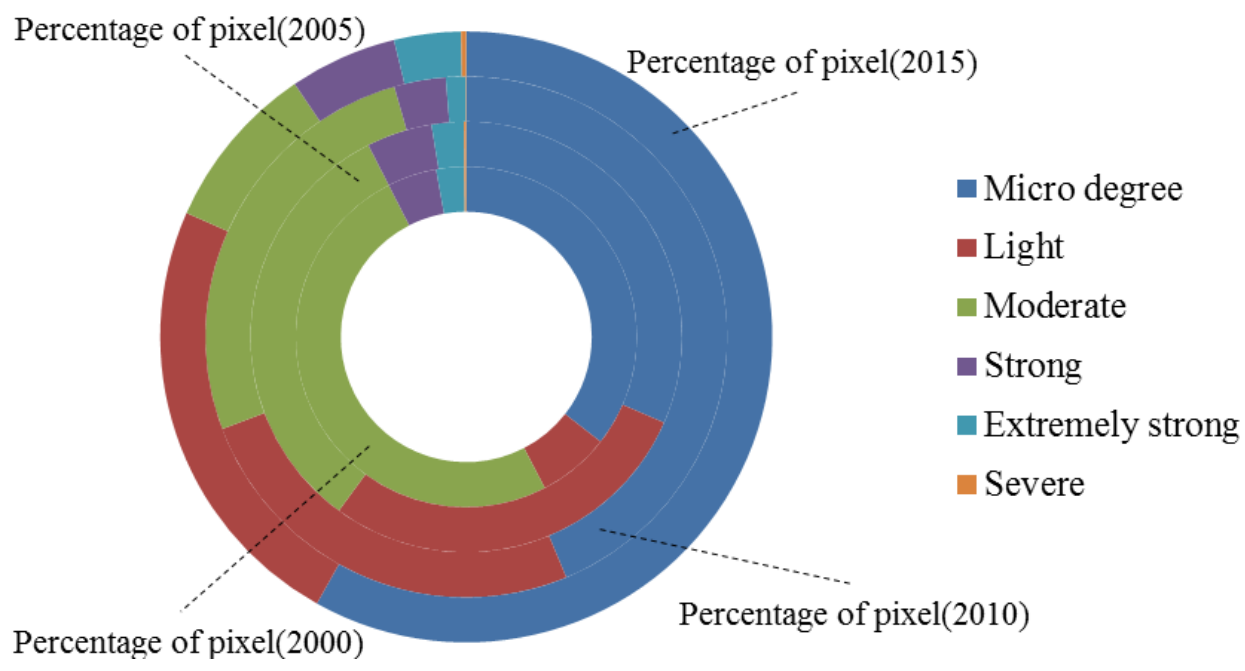

Figure 8. Statistics of grade pixel number of soil erosion in the lower reaches of the Chishui River Basin from 2000 to 2015 


\section{Trend analysis}

Through the results of the soil erosion modulus (A) sequence fitting, we could find that from 2000 to 2015, the number of pixels with a changing slope greater than 0 was 14849 , accounting for a region of $34.8 \%$ of the total area, and the soil erosion in these areas was increasing. The remaining 27824 pixels change slope was less than 0 , which accounted for $65.2 \%$ of the total area (Fig. 9a). The results of F test (Fig. 9b) showed that the number of pixels with a significant increase in soil erosion was $2564(X>0, P \leq 0.05)$, accounting for $6.14 \%$ of the total number of pixels. The region is mainly concentrated in several villages and towns on the border between Xuyong and Gulin, such as Guihua Town, Helemiao Town, Dazhaimiao Town, Huangjing Town, etc., as well as Zihua Town, Tiantangba Town, and Fubao Town in Hejiang County. The number of pixels with a significant reduction in soil erosion was $12284(\mathrm{X}<0, \mathrm{P} \leq 0.05)$, accounting for $29.43 \%$ of the total number of pixels. This type was scattered all over the study area, most concentrated in the Daqiao town, Baisha Town, Wanglong Town, Rongshan town and Yaoba town in the northwest direction of Hejiang County.
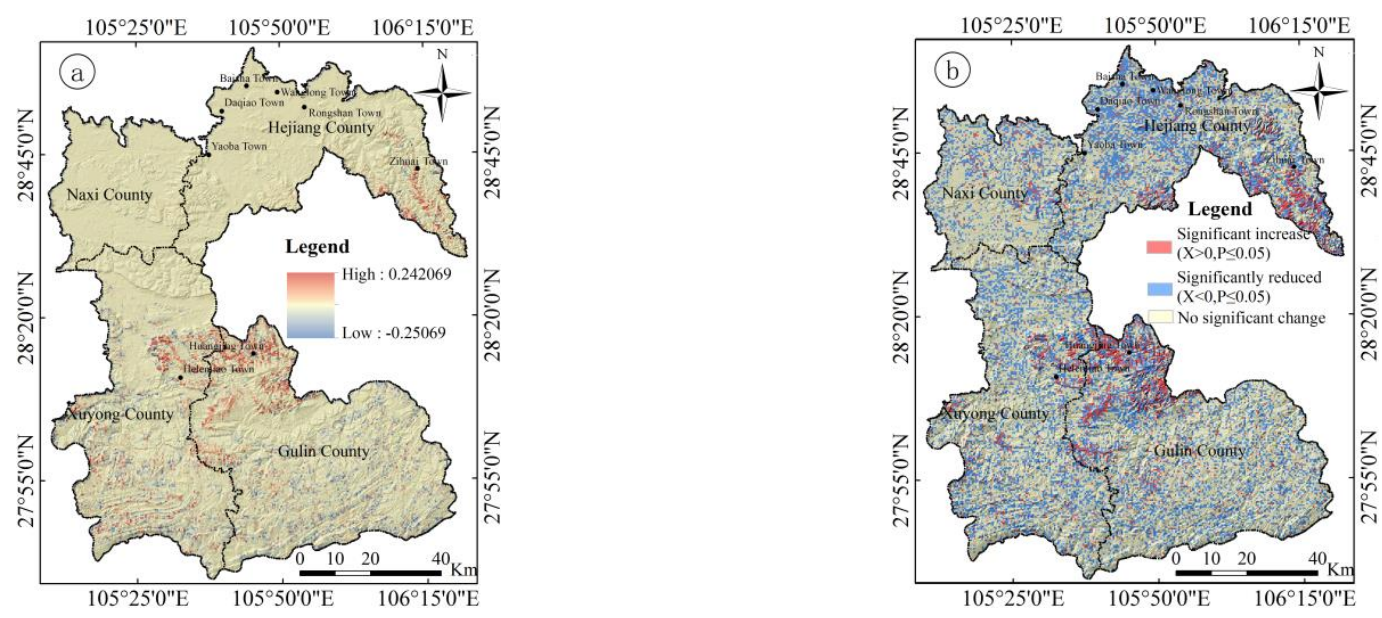

Figure 9. Variation trend of soil erosion (a) and significance test of the trend (b) in the lower reaches of the Chishui River Basin

\section{Quantitative attribution of soil erosion based on Geographical Detector}

From the results of the factor detector (Fig. 10) the main driving force factors' validity of the lower reaches of the Chishui River were compared from 2000 to 2015. From the time distribution of the mean value based on the main driving factors and the degree of soil erosion in the lower reaches of the Chishui River, it was concluded that there are significant driving factors and explanatory strengths: soil erodibility, the intensity of the fourth-stage soil erosion interpretation is greater than 0.15 , and the other factors are not more than 0.1 . Soil erodibility has the greatest quantitative interpretation of soil erosion in the lower reaches of the Chishui River Basin. Soil is the main target of erosion. Soil erodibility shows the greatest temporal similarity between soil erosion results in the lower reaches of the Chishui River Basin. Erodibility plays a leading role in soil erosion in the lower reaches of the Chishui River Basin. The more obvious the spatial distribution difference of the slope in the basin is, the more easily the rainwater will form a runoff and then cause water erosion. Therefore, the interpretation of soil erosion in the basin is followed by factors such as rainfall erosivity, slope, and soil and water conservation measures. 

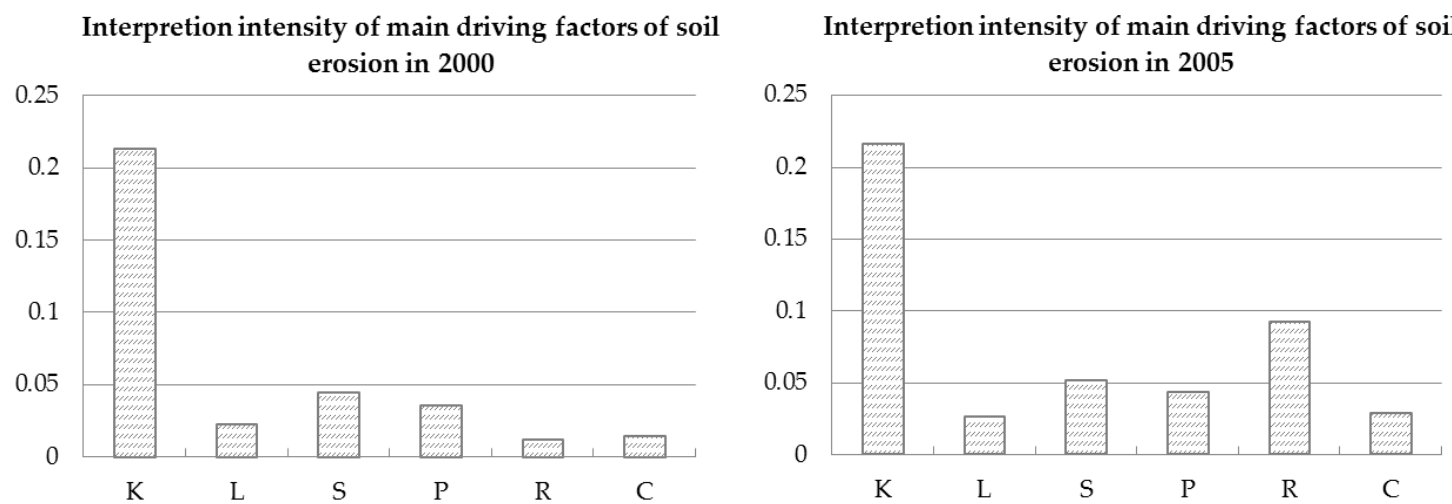

Interpretion intensity of main driving factors of soil erosion in $\mathbf{2 0 1 0}$

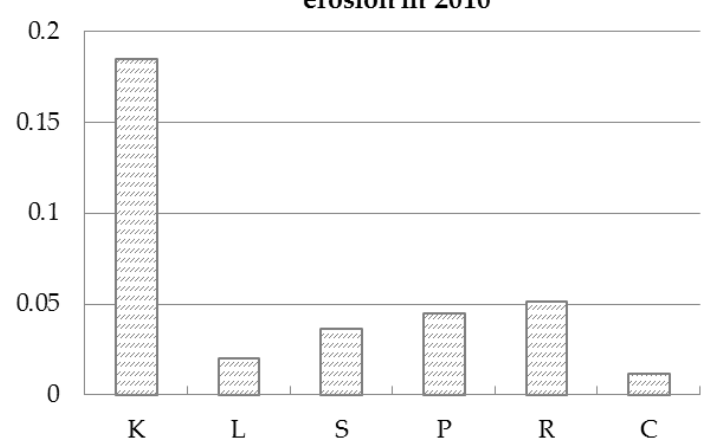

Interpretion intensity of main driving factors of soil erosion in 2015

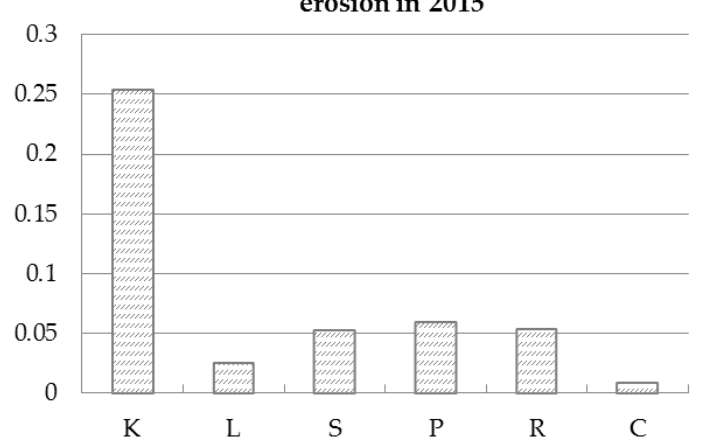

Figure 10. Interpretation intensity of main driving factors of soil erosion in the lower reaches of Chishui River Basin from 2000 to 2015 (K: Soil erodibility factor; L: Slope length factor; S: Slope factor; $P$ : Soil and water conservation practice factor; R: Rainfall erosivity factor; $C$ :

Vegetation cover management factor)

\section{Discussion}

The Chishui river basin has always been an important waterway for shipping and transportation since ancient times. The state council attaches great importance to the protection of the basin and the rational utilization and development of regional water conservancy. In this paper, the commonly used trend change analysis method for the ecological environment is combined with the soil loss correction model (RUSLE). The selected model factors can reflect the impact of natural factors and human factors on soil and water loss. Due to the uncertainty of natural factors in different years within the study time interval, soil erosion in some regions is sometimes very bad. The changing trend of multi-period image soil erosion in the study area can be visualized by using the slope-changing method.

The assessment of soil erosion at watershed scales is vital for sustainable land use planning (Ostovari et al., 2017). According to Ganasri and Ramesh (2016), moderate erosion is mostly concentrated in the location of agricultural areas with gentle slope in the watershed study area. The early grade of soil erosion in the Chishui River Basin was mainly moderate. This was because the population growth in the study area at that time increased the development and utilization of agricultural and forestry resources, especially the demand for slope cropland. Irrational farming methods have a strong disturbance on the soil, which has changed and destroyed the soil structure and its erosion resistance. Due to the lack of vegetation cover and bare soil, wasteland is prone to soil and water loss under the influence of external forces such as precipitation 
(Zerihun et al., 2018). The non-productive land in the study area is mostly residential land, highway land, etc., because the ground has hardened, the erosion modulus is very small.

From the relevant contents of the "Chishui River Cascade Hydropower Development" in "Report on the Key Points of the Comprehensive Utilization Plan of the Yangtze River Basin" in 1991, to the 2004 China Environment and Development International Cooperation Committee Basin Management Group set "Promoting Integrated River Basin Management and Rebuilding the River of Life in China", About regarding the selection of the Chishui River Basin to carry out the pilot work of integrated river basin management, the formulation of the Regulations on the Management and Protection of the Chishui River Basin and the Comprehensive Planning of the Chishui River Basin, etc., were planned for the comprehensive blueprint of soil erosion in Sichuan in 2017. The Chishui River is a national-level key area for soil erosion and a series of ecological protection and construction projects such as "natural forest protection" and "returning farmland to forests" implemented by the Chinese government in the basin. The prevention and control of soil erosion in this area had a positive effect. Since the implementation of a series of beneficial ecological measures such as "returning farmland to forests" in the research area in 2000, the overall situation of soil and water loss has been greatly alleviated. However, during the whole research stage, there was still an increasing trend of soil and water loss in some areas, which was due to the increasing area of soil and water loss caused by current production activities. The Chishui river basin is rich in rainfall, especially in summer when the intensity of rainstorm is extremely high. The main soil types in this area are yellow soil and paddy soil with good water retention, which is beneficial to strengthen the fundamental construction of farmland. In the future, sloping farmland management should be given priority to, the management of existing forest land should be strengthened, and the key areas of population concentration should be controlled, to maintain the benign cycle of ecological environment in the study area.

\section{Conclusion}

This paper combines the trend change analysis method commonly used in the ecological environment research with the soil loss correction model (RUSLE). The selected model factors can reflect the intuitive influence of natural and man-made factors on soil erosion. During the study interval, uncertain changes in natural factors in different years resulted in changeable soil erosion status. The change slope method can directly show the trend of a multi-phase image change in the study area.

(1) Judging from the comprehensive evaluation of soil erosion sensitivity in the lower reaches of the Chishui River Basin, the early stage of soil erosion in the region is mainly dominated by moderate erosion, the areas of light and soil loss in the later period are gradually increasing, mainly distributed in some areas in the north. The area is a parallel fold extension zone in eastern Sichuan. It belongs to the southern margin of the hilly Middle Sichuan area. Most of them are agricultural areas, and their soil water retention is good, and their slopes are low. Moderate soil erosion areas are widely distributed in most of the mid-altitude areas of Xuyong County and Naxi County; The strong and extremely strong soil erosion areas are concentrated in the low-middle mountain areas in the south, including most of the areas in Xuyong County and Gulin County, and a small part of Hejiang County. The exposed strata are dominated by 
limestone and mudstone, and the slope of the ground is large. Unutilized land and lowcoverage grasslands are densely populated here.

(2) Cultivated land and forest land are still the most important types of land use in the basin study area. The terrain is broken, and the topography is steep. Besides, the rainfall in the Chishui River Basin is relatively rich, which leads to potential soil erosion in the region.

(3) The change slope method was used to study the trend of soil erosion in the study area during the period from 2000 to 2015. The area where soil erosion is significantly increased $(\mathrm{X}>0, \mathrm{P} \leq 0.05)$ accounts for $6.14 \%$ of the total area. The area where soil erosion is significantly increased $(\mathrm{X}<0, \mathrm{P} \leq 0.05)$ accounts for $29.43 \%$ of the total area, and there was no significant change in the remaining areas. The results of the study fully demonstrate that long-term governance has achieved initial results.

(4) Geo-detectors were used to quantitatively analyze the strength of the main driving factors of the fourth-stage soil erosion results. Soil erodibility is the most explanatory factor among all driving factors. It played a leading role in the process of soil erosion in the lower reaches of the Chishui River Basin during the past 15 years.

(5) As a traditional method for observing soil erosion, the artificial field survey is time-consuming, labor-intensive, and requires a large amount of funds. It is only suitable for small areas. We combine RUSLE with Remote Sensing and Geographic Information Systems to achieve long-term soil erosion research in large areas. In the future, we plan to introduce landscape pattern, a landscape ecology research category, to study the distribution characteristics and evolution of soil erosion. From the perspective of landscape ecology, soil erosion is regarded as a spatial arrangement and combination of patch types with different erosion levels, which is the product of the merger of different soil erosion levels in space. The purpose of establishing the relationship between soil erosion and landscape pattern is to analyze the temporal and spatial characteristics of soil erosion in the study area from the perspective of landscape ecology, and use landscape pattern index to describe the characteristics of soil erosion types.

Acknowledgements. This research was funded by the National Natural Science Foundation of China (Grants No. 51609209) and the Education Department of Sichuan Province (Grants No. 18ZA0061).

\section{REFERENCES}

[1] Abdulkareem, J. H., Pradhan, B., Sulaiman, W. N. A., Jamil, N. R. (2019): Prediction of spatial soil loss impacted by long-term land-use/land-cover change in a tropical watershed. - Geoscience Frontiers 10(2): 389-403.

[2] Abidin, R. Z., Sulaiman, M. S., Yusoff, N. (2017): Erosion risk assessment: a case study of the Langat River bank in Malaysia. - International Soil and Water Conservation Research 5(1): 26-35.

[3] Alexakis, D. D., Hadjimitsis, D. G., Agapiou, A. (2013): Integrated use of remote sensing, GIS and precipitation data for the assessment of soil erosion rate in the catchment area of "Yialias" in Cyprus. - Atmospheric Research 131: 108-124.

[4] Anache, J. A. A., Flanagan, D. C., Srivastava, A., Wendland, E. C. (2018): Land use and climate change impacts on runoff and soil erosion at the hillslope scale in the Brazilian Cerrado. - Science of The Total Environment 622-623: 140-151. 
[5] Bera, A. (2017): Assessment of soil loss by universal soil loss equation (USLE) model using GIS techniques: a case study of Gumti River Basin, Tripura, India. - Modeling Earth Systems and Environment 3(1): 29.

[6] Borrelli, P., Robinson, D. A., Fleischer, L. R., Lugato, E., Ballabio, C., Alewell, C., Meusburger, K., Modugno, S., Schütt, B., Ferro, V., Bagarello, V., Oost, K. V., Montanarella, L., Panagos, P. (2017): An assessment of the global impact of 21st century land use change on soil erosion. - Nature Communications 8(1): 2013.

[7] Buttafuoco, G., Conforti, M., Aucelli, P. P. C., Robustelli, G., Scarciglia, F. (2012): Assessing spatial uncertainty in mapping soil erodibility factor using geostatistical stochastic simulation. - Environmental Earth Sciences 66(4): 1111-1125.

[8] Cai, C. (2000): Study of applying USLE and geographical information system IDRISI to predict soil erosion in small watershed. - Journal of Soil Water Conservation 14(2): 1924.

[9] Cai, H., He, Z. W., An, Y. L., Zhang, C., Deng, H. (2015): Response relationship between land use and water quality in Chishui river basin based on RS and GIS. Resources \& Environment in the Yangtze Basin 24(2): 286-291.

[10] Cerdà, A., Rodrigo-Comino, J., Novara, A., Brevik, E. C., Vaezi, A. R., Pulido, M., Giménez-Morera, A., Keesstra, S. D. (2018): Long-term impact of rainfed agricultural land abandonment on soil erosion in the Western Mediterranean basin. - Progress in Physical Geography: Earth and Environment 42(2): 202-219.

[11] Chen, G. B., Tong, X. S. (2012): Temporal and spatial change of urban air quality in Luzhou from 2004 to 2009. - Environmental Science \& Technology 35(6I): 217-220.

[12] Cunha, E., Bacani, V., Panachuki, E. (2017): Modeling soil erosion using RUSLE and GIS in a watershed occupied by rural settlement in the Brazilian Cerrado. - Natural Hazards 85(2): 851-868.

[13] Das, B., Paul, A., Bordoloi, R., Tripathi, O. P., Pandey, P. K. (2018): Soil erosion risk assessment of hilly terrain through integrated approach of RUSLE and geospatial technology: a case study of Tirap District, - Arunachal Pradesh. Modeling Earth Systems and Environment 4(1): 373-381.

[14] Efthimiou, N. (2018): Evaluating the performance of different empirical rainfall erosivity (R) factor formulas using sediment yield measurements. - Catena 169: 195-208.

[15] Fenta, A. A., Yasuda, H., Shimizu, K., Haregeweyn, N., Negussie, A. (2016): Dynamics of soil erosion as influenced by watershed management practices: a case study of the Agula watershed in the semi-arid highlands of northern Ethiopia. - Environmental Management 58(5): 1-17.

[16] Fu, G., Chen, S., McCool, D. K. (2006): Modeling the impacts of no-till practice on soil erosion and sediment yield with RUSLE, SEDD, and ArcView GIS. - Soil and Tillage Research 85(1): 38-49.

[17] Ganasri, B. P., Ramesh, H. (2016): Assessment of soil erosion by RUSLE model using remote sensing and GIS - a case study of Nethravathi Basin. - Geosci Front 7: 953-961.

[18] Gogichaishvili, G. P., Kirvalidze, D. R., Gorjomeladze, O. L. (2014): Testing of the hydromechanical prediction model of soil erosion under the conditions of Georgia. Eurasian Soil Science 47(9): 917-22.

[19] Hickey, R., Smith, A., Jankowski, P. (1994): Slope length calculations from a DEM within ARC/INFO grid. - Computers, Environment and Urban Systems 18(5): 365-380.

[20] Karydas, C. G., Sekuloska, T., Silleos, G. N. (2009): Quantification and site-specification of the support practice factor when mapping soil erosion risk associated with olive plantations in the Mediterranean island of Crete. - Environmental Monitoring and Assessment 149(1): 19-28.

[21] Kavian, A., Sabet, S. H., Solaimani, K., Jafari, B. (2015): Simulating the effects of land use changes on soil erosion using RUSLE model. - Geocarto International 32(1): 97-111. 
[22] Kayet, N., Pathak, K., Chakrabarty, A., Sahoo, S. (2018): Evaluation of soil loss estimation using the RUSLE model and SCS-CN method in hillslope mining areas. International Soil and Water Conservation Research 6(1): 31-42.

[23] Khaledian, Y., Kiani, F., Ebrahimi, S., Brevik, E. C., Aitkenhead-Peterson, J. (2017): Assessment and monitoring of soil degradation during land use change using multivariate analysis. - Land Degradation \& Development 28(1): 128-141.

[24] Kosmas, C., Gerontidis, S., Marathianou, M. (2000): The effect of land use change on soils and vegetation over various lithological formations on Lesvos (Greece). - Catena 40(1): 51-68.

[25] Kosmowski, F. (2018): Soil water management practices (terraces) helped to mitigate the 2015 drought in Ethiopia. - Agricultural Water Management 204: 11-16.

[26] Krellenberg, K., Welz, J. (2017): Assessing urban vulnerability in the context of flood and heat hazard: pathways and challenges for indicator-based analysis. - Social Indicators Research 132(2): 709-731.

[27] Lakkad, A. P., Patel, G. R., Sondarva, K. N., Shrivastava, P. K. (2018): Estimation of sediment delivery ratio at sub-watershed level using revised and modified USLE. Agricultural Science Digest 38(1): 11-16.

[28] Leys, A., Govers, G., Gillijns, K., Berckmoes, E., Takken, I. (2010): Scale effects on runoff and erosion losses from arable land under conservation and conventional tillage: the role of residue cover. - Journal of Hydrology 390(3): 143-154.

[29] Liu, B. Y., Nearing, M., Shi, P. J., Jia, Z. W. (2000): Slope length effects on soil loss for steep slopes. - Soil Science Society of America Journal 64: 1759-1763.

[30] Mahala, A. (2018): Soil erosion estimation using RUSLE and GIS techniques - a study of a plateau fringe region of tropical environment. - Arabian Journal of Geosciences 11(13): 335.

[31] Mondal, A., Khare, D., Kundu, S. (2018): A comparative study of soil erosion modelling by MMF, USLE and RUSLE. - Geocarto International 33(1): 89-103.

[32] Montgomery, D. R. (2007): Soil erosion and agricultural sustainability. - Proceedings of the National Academy of Sciences 104(33): 13268 LP-13272.

[33] Ochoa, P. A., Fries, A., Mejía, D., Burneo, J. I., Ruíz-Sinoga, J. D., Cerdà, A. (2016): Effects of climate, land cover and topography on soil erosion risk in a semiarid basin of the Andes. - CATENA 140: 31-42.

[34] Osouli, A., Bahri, P. S. (2018): Erosion rate prediction model for levee-floodwall overtopping applications in fine-grained soils. - Geotechnical and Geological Engineering 36(5): 2823-2838.

[35] Ostovari, Y., Ghorbani-Dashtaki, S., Bahrami, H. A., Naderi, M., Dematte, J. A. M. (2017): Soil loss estimation using RUSLE model, GIS and remote sensing techniques: a case study from the Dembecha Watershed, Northwestern Ethiopia. - Geoderma Regional 11: 28-36.

[36] Panagos, P., Katsoyiannis, A. (2019): Soil erosion modelling: the new challenges as the result of policy developments in Europe. - Environmental Research 172: 470-474.

[37] Pham, T. G., Degener, J., Kappas, M. (2018): Integrated universal soil loss equation (USLE) and Geographical Information System (GIS) for soil erosion estimation in A Sap basin: Central Vietnam. - International Soil and Water Conservation Research 6(2): 99110.

[38] Preetha, P. P., Al-Hamdan, A. Z. (2019): Multi-level pedotransfer modification functions of the USLE-K factor for annual soil erodibility estimation of mixed landscapes. Modeling Earth Systems and Environment 5(3): 767-779.

[39] Rammahi, A. H. J. A., Khassaf, P. D. S. (2018): Estimation of soil erodibility factor in rusle equation for euphrates river watershed using GIS. - International Journal of GEOMATE 14: 164-169. 
[40] Rodrigo-Comino, J., Ruiz-Sinoga, J. D., Senciales-González, J. M., Guerra-Merchán, A., Seeger, M., Ries, J. B. (2016): High variability of soil erosion and hydrological processes in Mediterranean hillslope vineyards (Montes de Málaga, Spain). - Catena 145: 274-284.

[41] Schmid, A. (2012): Spatial and temporal variability of rainfall erosivity factor for Switzerland. - Hydrology \& Earth System Sciences Discussions 16: 167-177.

[42] Sheng, H. Y., Shi, X. J. (2001): Geological background of soil and water erosion and water conservation problems. - Soil and Water Conservation Science and Technology in Shanxi 3: 15-17.

[43] Singh, G., Panda, R. K. (2017): Grid-cell based assessment of soil erosion potential for identification of critical erosion prone areas using USLE, GIS and remote sensing: a case study in the Kapgari watershed, India. - International Soil and Water Conservation Research 5(3): 202-211.

[44] Torri, D., Poesen, J., Borselli, L. (1997): Predictability and uncertainty of the soil erodibility factor using a global dataset. - Catena 46(4): 309-310.

[45] Uri, N. D. (2001): A note on soil erosion and its environmental consequences in the United States. - Water Air \& Soil Pollution 129(1-4): 181-197.

[46] Vaezi, A. R., Zarrinabadi, E., Auerswald, K. (2017): Interaction of land use, slope gradient and rain sequence on runoff and soil loss from weakly aggregated semi-arid soils. - Soil and Tillage Research 172: 22-31.

[47] Wang, J. F., Xu, C. D. (2017): Geodetector: principle and prospective. - Acta Geographica Sinica 72: 116-134.

[48] Wang, Y., Wang, G. Q. (2011): A study of distribution regularity of soil erosion in Sichuan Province. - Scientific \& Technological Management of Land \& Resources 28(6): 50-55.

[49] Wang, Z. S., Jiang, L. G., Huang, M. J., Zhang, C., Yu, X. B. (2007): Biodiversity status and its conservation strategy in the Chishui river basin. - Resources \& Environment in the Yangtze Basin 16(2): 175-180.

[50] Wijesundara, N. C., Abeysingha, N. S., Dissanayake, D. M. S. L. B. (2018): GIS-based soil loss estimation using RUSLE model: a case of Kirindi Oya river basin, Sri Lanka. Modeling Earth Systems and Environment 4(1): 251-262.

[51] Wischmeier, W. H. (1965): Predicting rainfall erosion losses from cropland east of the Rocky Mountain. - Agriculture Handbook 282: 47.

[52] Wu, Y., Xie, Y., Zhang, W. B. (2001): Comparison of different methods for estimating average annual rainfall erosivity. - Journal of Soil Water Conservation 15(3): 31-34.

[53] Yang, J., Guan, Y., Li, X. M., Xi, J. C. (2018): Urban fringe area ecological vulnerability space-time evolution research: the case of Ganjingzi District, Dalian. - Acta Ecologica Sinica 38(3): 388-405.

[54] Zerihun, M., Mohammedyasin, M. S., Sewnet, D., Adem, A. A., Lakew, M. (2018): Assessment of soil erosion using RUSLE, GIS and remote sensing in NW Ethiopia. Geoderma Regional 12: 83-90. 